\title{
DESIGNING DIGITAL TEACHING MEDIA FOR MILLENNIAL TEACHERS: TRENDS AND SENSE
}

\author{
Sri Haryati ${ }^{1}$, Dewi Cahyaningrum ${ }^{2}$ \\ nafisahatiku@staff.uns.ac.id \\ Sebelas Maret University ${ }^{1,2}$
}

\begin{abstract}
Digital-based teaching media possess very high production quality capable of showcasing complex ideas in a short period of time. Later, the digital-based teaching media is well developed in millennial era indicating by the productivity escalation of it. This study aim at investigating (1) the trending application resorted by the teaching media designers to create the digital-based teaching media; (2) the problems faced by millennial teachers in creating the digital-based teaching media; (3) the underlying factors of the problems; (4) the efforts of digital teaching media designers to overcome the problems. Using descriptive qualitative, the 129 digital teaching media designers (millennial teachers) within 22-37 years old were investigated about the process and the product of digital-based teaching media. Questionnaire, interview, and document analysis used to assemble the data. The data were analyzed using the Interactive Model of data analysis. Triangulation technique facilitated the data validation and verification later. The result of the research shows that (1) the there are trending applications resorted by designer to create the digital teaching media such as prezi, movie maker and kine toon; (2) Less creativity and understanding towards technology become the major problems; (3) The lack of knowledge in technology and the dependency to make use the ready-made digital teaching media be the prominent factors causing the problem in designing digital teaching media; (4) Enhancing the creativity, innovation and technology sensitivity is the top solution proposed by teachers. The research implies that being the digital teaching media developers need extra efforts. Moreover, improving the technology sensitivity towards the current technology for teaching assists the designer better.
\end{abstract}

Keywords: digital-based teaching media; millennial era; technology sensitivity

\section{INTRODUCTION}

The use of technology in education has been beneficial for teachers to facilitate students' learning. According to Baker et al. (2000), in the 21 st century, as people spend more time watching television and using computers, our culture is becoming more technological. In this case, Davies (2014) stresses one of the major roles of the 21 st century teachers today should try to teach their students how to find and work with information. Here, when a teacher uses the media primarily for the purpose of teaching, he or she also indirectly teaches media literacy requested by 21 st century era. The teacher trains the students to be 
successful information seekers who can interpret the content media offer well and know how to process the information for their own benefit.

Davies (2014) underlies that the success of the teaching process lies in the understanding of the changing of students' learning styles and teachers' readiness to adapt their teaching techniques accordingly. It is obvious that the 21 st century students who have been born into the digital age have their own lifestyles noted have changed quite much from the previous generations. Erbaggio et al. (2014) call these students as 'the NetGen' who are "typically visually literate, having the unique ability to weave together images, text, and sound in a natural way, and to assimilate disparate information from multiple sources". Moreover, Spector et al. (2013) call these students as 'digital natives' who are different from their parents and teachers referred to as 'digital immigrants'. Since these students have a sophisticated knowledge of and skills with information technologies and experiences with technology, they have particular learning preferences or styles that differ from earlier generations of students" (Osborn, 2003). It can be underlined here that the lives of the current generation is determined by internet becoming a prominent learning tool and a primary source for information (Lawless, 2007).

Facing the students who have changed quite much in recent years, teachers cannot stay mostly the same. Teachers ideally adapt their teaching techniques to fit the students' needs and the needs of the society they live in. In this case, millennial teacher, theoretically, is considered to be able to create digital-based teaching media since they have high technology sensitivity which enables them to catch the technology renewal and exploit it for any purpose. On the other side, the usage of digital teaching media assists teachers in the whole teaching stages namely warming up, presentation, practice, production and summing up. Moreover, the learning process will be more interesting because the educators will easily find huge information on the internet. Students can also learn by them self independently. Lastly, digital teaching media can facilitate students' different level of competence (Mayer, 2001; Cai, 2012).

The word media is from Latin language "medium" that means carrier the information from a source to a receiver. There are a lot of examples of teaching media such as video, television, diagram, printed material and also internet communication tools that are considered as instructional media since they provide messages with instructional purpose. Digital-based teaching media in this context acknowledge the opportunities created by the confluence of the World Wide Web (internet), mobile technologies, film, video games, TV, comics, and also software facilitating students' learning.

In general, both teaching and learning are facilitated through the application of cyber technologies in form of digital-based teaching media. There are many applications that are popular among teachers such as prezi, movie maker, songong, quiz based fighting and kine toon. These application are considered helpfull for both teachers and students. Students learn faster and easier than before because technologies as internet have always been interesting to them. In this case Scholz (2013) states that teachers need to consider how to engage learners with content by connecting to their current interests as well as their technological habits and 
dependencies. According to Buckingham (2007) students' uses of computers in the home are massively dominated by video games and leisure uses of the internet becoming increasingly significant. In this case, teachers need to initiate the use of digital 'edutainment' materials, or to incorporate the latest technological gadgets that are often proven superficial for students.

Besides, digital-based teaching media makes communication available and fun and removes the barrier of location for people in different parts of the world. Digital-based teaching media also possess very high production quality capable of showcasing complex ideas in a short period of time. Moreover, Yellend (2001) points out that adherence to traditional teaching methods fails to adequately support learners in developing the skills required for success in today's technology-driven society where English learners have few occasions to practice their communicative skills in an authentic, interactive environment. Furthermore, the 21st century students should be not only taught with the new media, but they should also know how to use them effectively. Osborn et al. (2003) state that the 21st century students may have some solid abilities to work with the electronic media, but it was proved that they still need training in using them effectively. Buckingham (2007) states that "the meaningful and effective use of media in education therefore depends upon students developing a form of critical media literacy that goes well beyond a training in how to operate the hardware or software". In this case, when the teachers integrate applications to produce digital teaching media, they need to equip students to understand and to critique these applications. They should not use them in a merely functional or instrumental way. Scholz (2013) adds that students need digital media fluency requiring an understanding of the moment when technological interfaces hinder learning and become distracting.

In reality, being familiar with the applications resorted by teacher to create digital teaching media and knowing the critical basis underlying the importance of integrating digital teaching media for students learning are not enough to be basis for designing Digital-based Teaching Media. Instead enhancing digital literacy, teachers need to develop creative production as well. Teachers exaggerate their mind to produce their own multimedia texts. For example, teachers may combine written text, visual images, simple animation, audio and video material, for example on topics in Science or History (Lachs, 2000). Instead enhancing digital literacy, teachers need to develop creative production as well. In brief, it can be said that to design digital-based teaching media, teachers should know both, media as a teaching aid and the study of media in their own right.

Based on the explanation above, it is known that living in digital era demands teachers for having many insights about technology which plays significant roles in the whole aspect of their life, including teaching. This study aims at investigating (1) the trending application resorted by the teaching media designers to create the digital-based teaching media; (2) the problems faced by millennial teachers in creating the digital-based teaching media; (3) the 
underlying factors of the problems; (4) the efforts of digital teaching media designers to overcome the problems.

\section{RESEARCH METHODOLOGY}

The current study aim at presenting the wealth of data obtained on trending apps or software-used by millennial teachers, the problems-faced, the causal factors as well as the efforts made to overcome the problems. The participants of the study were 129 millennial English teachers (around 22-37 years old) consisting 81 (63\%) male and 48 (37\%) female teachers. Qualitative research methods were adopted in this study. Questionnaire and indepth interview was conducted to attain the data. Closed and open questions were made in the questionnaire. The semi structured interview was conducted to teachers in attempt to achieve the meaningful insight of the teachers problems in producing digital teaching media and their effort to overcome the problems. The verbal data gotten from semi-structured interview were analyzed qualitatively adopting the model of Miles and Hubermen (1984) which underwent the complete procedures of data reduction, data display, conclusion drawing and verification. Triangulation of source and method is implemented as an attempt to reassure the validity of the data.

\section{RESULT AND DISCUSSION}

\section{Trending Apps for Designing Digital Teaching Media}

Technology plays the significant roles in education particularly in millennial or gadgetry era where the beneficial applications used in every aspect of life. In teaching, technology becomes an important aspect, starting from the way teachers prepare the learning process until the step when students understand and master the materials. Moreover, main role of educational technology is it lets teacher to take a chance to design her or his own learning material with a technology (Bennett, Maton, and Kervin: 2008).

The beneficial aspects of using technology in teaching, then, escorted teachers to create and perform technology in classroom. These hard exertions were made merely to optimize the students' achievement and obtained the desired learning goal(s). The result of the questionnaire revealed that the vast majority of the participants (54.8\%) "frequently" design the digital based teaching media, and those who "often" design digital teaching media were $23.8 \%$. The rest of the participants $(21.4 \%)$ categorized as "sometimes" in designing digital teaching media.

Mostly, teachers as digital teaching media designer made use of digital collaborative learning which employ some learning media such as collaborative social learning platform websites, wiki- and web page-creation tools (Google Site), animated videos (mostly taken from youtube) and ready used online apps (software) as visualized in Table 1. 
Table 1.Trending Apps for Designing Digital Teaching Media

\begin{tabular}{clcc}
\hline No & \multicolumn{1}{c}{ Application } & Occurrences & Percentage \\
\hline 1 & Prezi & 44 & $33.85 \%$ \\
2 & Movie Maker & 22 & $16.92 \%$ \\
3 & Wondershare Quiz Creator & 18 & $13.85 \%$ \\
4 & Kine Master & 14 & $10.77 \%$ \\
5 & Adobe Flash & 8 & $6.15 \%$ \\
6 & Macromedia Flash Player & 6 & $4.62 \%$ \\
7 & Powtoon & 6 & $4.62 \%$ \\
8 & Quiz based Fighting & 4 & $3.08 \%$ \\
9 & Izahime & 2 & $1.54 \%$ \\
10 & Corel Video Studio & 2 & $1.54 \%$ \\
11 & Premiere & 2 & $1.54 \%$ \\
12 & Inspring Quiz Maker & 2 & $1.54 \%$ \\
\hline & Total & $\mathbf{1 3 0}$ & $\mathbf{1 0 0 \%}$ \\
\hline
\end{tabular}

Table 1 showed that Prezi (the presentation software that uses motion, zoom, and spatial relationship) put in the first rank of trending apps used in designing digital teaching media. It was followed by Movie Maker (16.92\%), Wondershare Quiz Creator (13.85\%), Kine Master (10.77\%), Adobe Flash (6.15\%), Macromedia Flash Player (6.15\%), Powtoon (6.15\%), Quiz based Fighting (3.08\%), Izahime, Corel Video Studio, Premiere and Inspring Quiz Maker with the equal percentage 1.54\%. Power Point Presentation (PPT) was admitted as the common software to create digital teaching media. The rank of trending apps above, regardless, related to teachers' background knowledge on technology used particularly in teaching as well as their technology sensitivity. The majority teachers got information about technology for teaching from internet (51.28\%). Others got information from communities (32.05\%), seminar and other presentations $(10.26 \%)$ and books $(6.41 \%)$.

Designing digital teaching media is assumed as tailoring and packaging complex information and learning activities to be more interested for students. This activity, of course, takes certain process and time. The time consumed for designing teaching media was revolved from the short one (an hour) until more than a week. The millennial teachers confessed that the length duration in designing digital based teaching media depended on several reasons. The complexity of teaching materials $(45.56 \%)$ and the software $(31.60 \%)$ was established by the significant percentage of the designers. On the other hand, the technology sensitivity received the small percentage (12.82\%) and motivation gained $10.27 \%$. Last, others factor such as deadline (available time), teachers' mood and the vigor of internet connection obtained 6.01\%.

\section{Designing Digital Teaching Media: Problems and Underlying Factors}

Designing digital teaching media was considered to be difficult at first. The designer, even, faced difficulties although they have created it for uncounted time. The result of the interview revealed that teachers found difficulties for certain cases as presented in Table 2. 
Table 2. Teachers' Problems in Designing Digital Teaching Media

\begin{tabular}{clc}
\hline No & \multicolumn{1}{c}{ Problems } & Percentage \\
\hline $\mathbf{1}$ & Intrinsic Problems & \\
\hline & Less understanding about the used-apps & $35.84 \%$ \\
& (software) & $10.68 \%$ \\
& Lack of time & $18.8 \%$ \\
\hline & Less creativity & \\
\hline $\mathbf{2}$ & Extrinsic Problems & $32.4 \%$ \\
& Complexity of the apps (software) & $2.28 \%$ \\
\hline
\end{tabular}

The significant percentage which categorized as the greatest problem faced by designers was "less understanding about the used-apps (software)" (35.84\%). This percentage followed by others problem such as "lack of time" gained $10.68 \%$ and "less creativity" reached 18.8\%. Those problems were categorized as intrinsic problem as stated by Hendren in Bigimlas (2009) who divides the technology barriers into two categories, intrinsic which refers to individuals such as teachers and student barriers and extrinsic which refers to organisational barriers. In addition, "the complexity of the apps (software)" which gained the great percentage $(32.4 \%)$ and "coding in certain software" admitted by the small number of participants (2.28) were the extrinsic problems faced by designers. The findings revealed that the main problems in production process coming from teachers. As stated by Koller, Harvey \& Magnotta (2001) that teachers get difficulties to use a higher level of technology.

Investigating the underlying factor(s) of the problems was needed to determine the possible solutions later. The causal factors of the problems in designing digital teaching media were accumulated in Table 3.

Table 3. Underlying Factor of the Problems in Designing Digital Teaching Media

\begin{tabular}{|c|c|c|}
\hline No & Coding of Underlying Factors & Occurrence(s) \\
\hline 1 & LoC-Lack of Creativity & 30 \\
\hline 2 & LoK-Lack of Knowledge & 27 \\
\hline 3 & LoP-Lack of Practice & 27 \\
\hline 4 & LoT-Lack of Time & 6 \\
\hline 5 & CoTM-Complexity of Teaching Materials & 3 \\
\hline 6 & $\begin{array}{l}\text { FtCbTMaM-Finding the Connection between } \\
\text { Teaching Materials and Media }\end{array}$ & 3 \\
\hline 7 & NC-No Colabolator & 3 \\
\hline \multirow[t]{2}{*}{8} & $\begin{array}{l}\text { SbCoMaTP-Synchronize between the Content of } \\
\text { Media and Teaching Plan }\end{array}$ & 3 \\
\hline & Total & 102 \\
\hline
\end{tabular}


Wising up the problems and causal factors of the problems, some efforts were made to overcome the problems. Most teachers (60\%) tried to update the knowledge about technology through book and internet such as finding the tutorials and reading the articles. Providing sufficient time has been proposed by numbers of teachers $(20 \%)$. Others effort such as getting more training in designing digital teaching media was done by some teachers $(10 \%)$ and updating the information from community which concern on technology for teaching reached $7.5 \%$. Only a teacher $(2.5 \%)$ tried to increase their creativity to overcome the problems.

There is no doubt that technology in teaching is an effective instrument because it is dynamic and it can develop well (Catheral, 2005). Therefore, teachers, functioned as education developer, compete to create the digital teaching media to increase the quality of instructional process and strengthen the collaborative teaching and learning (Kozma, 2003). The digital teaching media were created by utilizing certain apps (software). Designing teaching media using apps is believed raising interest since it facilitates teaching and learning and supports students' and educators' scientific inquiry (Johnson et al, 2012; Price et al in Shu\&Ching, 2013).

The production process of digital teaching media is normally followed by numbers of problems. First-order barriers to computer implementation, extrinsic in nature, include access to computers, software availability and quality, planning time, and technical support. In contrast, second order barriers to computer usage are typically intrinsic in nature. Second order barriers include beliefs about teaching, instructional models, belief about technology, and openness to change (Brickne, 1995). Some efforts need to be made to overcome the problems. One of the proposed exertions is given the training to increase their competence especially in using technology to support the teaching and learning process (Coghlan 2004; Lai \& Kritsonis 2006; Schwab \& Foa 2001).

\section{CONCLUSION}

There is no doubt that digital teaching media facilitates students to gain more knowledge and information around the world thus the production needs to be increased. This study highlight the trending application resorted by the teaching media designers to create the digital-based teaching media, the problems faced by millennial teachers in creating the digital-based teaching media and the underlying factors and the efforts made to overcome the problems. The result of the study indicates several apps (software) used to create digital teaching media namely Prezi, Movie Maker, Wondershare Quiz Creator, Kine Master, Adobe Flash, Macromedia Flash Player, Powtoon, ,Quiz based Fighting, Izahime, Corel Video Studio, Premiere and Inspring Quiz Maker. In production process, teachers as teaching media designers faced intrinsic and extrinsic problems. Those problems were caused by eight factors namely lack of creativity, lack of knowledge, lack of practice, complexity of teaching materials, finding the connection between teaching materials and media, single designer, synchronizing the connection between teaching materials and media. Considering the problems and underlying factors, some efforts have been made by millennial teachers to eliminate them. 


\section{ACKNOWLEDGEMENT}

The data were assembled from English teachers within 22-27 years old from several schools in Java. We thank for the participants and our colleagues for their valuable input. We also thank to LPPM of Sebelas Maret University for the funding supports.

\section{BIBLIOGRAPHY}

Baker, Elizabeth et al. "Audience Awareness in Technology-Rich Elementary Classroom.” Journal of Literacy Research. September 2000: 395-419.

Bingimlas, K.The barriers to the successful integration of ICT in teaching and learning environments: A review of the literature. Eurasia Journal of Mathematics, science and technology education 2009, 5 (3). Retrieved from : https://eric.ed.gov/?id=EJ905676

Buckingham, D. (2007). Media education goes digital: an introduction, Learning, Media and Technology, 32:2, 111-119, DOI: 10.1080/17439880701343006

Cai, H. (2012). E-learning and English Teaching. IERI Procedia, Vol. 2, 841-846. doi:10.1016/j.ieri.2012.06.180

Catherall,P., Skills exchange experience by students in the use of education technology/elearning. Power point presentation. Retrieved from : slideplayer.com/slide/6417964/

Coghlan, B. F. (2004). Addressing the barriers to technology interaction: A case study of a rural school, PhD Dissertation, Department of Curriculum and Instruction, Mississippi State University, Mississippi.

Davies, Gareth. "Changing with the Times" [webinar]. OUP 30 January 2014. 30 January 2014

$<$ https://elt.oup.com/teachers/professionalDevelopment/webinarsarchive $\mathrm{cc}=\mathrm{cz}$ \&sellanguage $=$ cs \&mode $=$ hub $>$

Erbaggio, Pierluigi et al. "Enhancing Student Engagement through Online Authentic Materials.” International Association for Language Learning Technology Vol. 42 $\begin{array}{llllll}\text { Nr. } & 2 & 2012 . & 10 & \text { March } & 2014\end{array}$ $<$ http://www.iallt.org/iallt_journal/enhancing_student_ engagement_through_online_authentic_materials $>$.

Johnson, L., Adams, S., \& Cummins, M. (2012). Mobile apps. The NMC horizon report: 2012 higher education edition. Austin, Texas: The New Media Consortium.

Koller, V., Harvey, S. \& Magnotta, M. 2001. Technology-based teaching strategies. Social Policy Public Research Association. New York.

Kozma, R. (Ed.) (2003). Technology and Classroom Practices: An International Study. Journal on research on technology in education

Lachs, V. (2000) Making multimedia in the classroom: a practical guide (London, Routledge). 
Lai, C. C., \& Kritsonis, W. A (2006). 'The advantages and disadvantages of computer technology in second language acquisition', Doctoral Forum: National Journal For Publishing And Mentoring Doctoral Student Research, vol. 3, no. 1, pp. 1-6.

Lawless, Kimberly et al. "Acquisition of Information Online: Knowledge, Navigation and Learning Outcomes." Journal of Literacy Research. September 2007: 911934.

Mayer, Richard E. (2001) Multimedia Learning, Cambridge: Cambrigde University Press.

Osborn, Marilyn et al. A World of Difference?. Buckingham: Open University Press, 2003.

Scholz, R. Trebor. Learning Through Digital Media Experiments in Technology and Pedagogy. The Institute for Distributed Creativity. 2013

Schwab, R. L. \& Foa, L. (2001). 'Integrating technologies throughout our schools', PHI Delta Kappan, vol. 82, pp. 620-626.

Shu, Yu-Chang \& Ching, Yu-Hui. (2013). Mobile App Design for Teaching and Learning: Educators' Experience in an Online Graduate Course. The International Review of Research in Open and Distance Learning 2013, 14 (4). Retrieved from https://files.eric.ed.gov

Spector, Michael et al. Handbook of Research on Educational Communications and Technology (4th edition). Springer Science \& Business, 2013.

Yellend, N. (2001). Teaching and learning with information and communication technologies (ICT) for numeracy in the early childhood and primary years of schooling. Canberra, Australia: Department of Education, Training and Youth Affairs. 
